\title{
Dynamics of morphological changes in neural cell culture with a model of neurotrauma in vitro under the influence of conditioned media of the rat fetal brain neurogenic cells
}

\author{
Pedachenko E. G., Liubich L. D., Staino L. P., Egorova D. M. \\ The State Institution «Romodanov Neurosurgery Institute, National Academy of Medical Sciences of Ukraine», Kyiv, Ukraine \\ e-mail: lyubichld@gmail.com
}

\section{ABSTRACT}

A potential strategy for recovery and regeneration of brain damage due to traumatic brain injury is considered to be the transplantation of neurogenic stem and/or progenitor cells (NSCS/NPCS). The key factors of the regenerative effects of NSCs/NPCs (so-called bystander effects) include the signal molecules produced by them into the extracellular environment (secretome).

The PURPOSE is to study the effects of the conditioned media of rat fetal brain neurogenic cells (FBNCS) in the in vitro model of neurotrauma.

MATERIALS AND METHODS. In neural cell culture of FBNCs from rat fetuses (E14-16), neurotrauma was modeled in vitro by mechanical scratching of monolayer and conditioned medium obtained from 24-h cultures of rat FBNCs was added. Cell phenotype was evaluated by morphological features and by immunocytochemical staining for Nestin and GFAP. The density and length of processes, migration capacity, the monolayer density and overgrowth cell rate in the scratched area were compared. Morphometric study included analysis of the width of the scratched area, the number of migrating cells, the distance of migration and mitotic activity in the intact monolayer.

RESULTS. Under the conditions of the nutrient medium of standard composition (DMEM with $20 \%$ fetal calf serum, $8 \mathrm{mg} / \mathrm{mL} \mathrm{g} / \mathrm{lucose}$ ) in a reproduced model of neurotrauma in vitro in the scratched area the signs of endogenous regeneration are shown during 24-48 $\mathrm{h}$ of cultivation. The overgrowth of cell processes from monolayer and short distance migration of single undifferentiated or poorly differentiated cells were shown. In the next 72-96 h of observation, the degeneration of migrated cells and processes in the scratched area was detected. Under the influence of conditioned media from 24-h cultures of FBNCs by single addition immediately after scratching at dose of $0.1 \mathrm{mg} / \mathrm{mL}$ for protein content the stimulation of regeneration was detected up to $7^{\text {th }}$ day of cultivation. The migration of cell processes from the monolayer simultaneously with undifferentiated or poorly differentiated cells at 24 hours was shown. The formation of cell clusters and their differentiation (at $48 \mathrm{~h}$ ), as well as monolayer growth of differentiated cells with partial or complete overgrowth of scratched area terminals (72-168 h) were observed. The morphological signs of degeneration of migrated cells in the scratched area appeared only on the $8^{\text {th }}$ day of cultivation. Conditioned media does not affect qualitative and quantitative properties of the culture of rat FBNCs in the intact area where mitotic activity was average.

CONCLUSIONS. Conditioned medium from 24-h cultures of rat FBNCS can stimulate reparation in the in vitro model of neurotrauma in neural cell culture for at least 7 days at a single addition, without affecting the cellular composition and mitotic activity of the intact monolayer.

KEY WORDS: neural cells culture; scratch assay; fetal brain neurogenic cells; conditioned media

Traumatic brain injury (TBI) as an intracranial injury to the brain caused by an external force due to severe impact is a global medical and socio-economic issue [1]. TBI leads to primary reversible or irreversible brain damage, causing secondary reactions at the ultrastructural, cellular, tissue, organ levels, which affect the whole body. The severity of clinical manifestations and consequences of TBI is determined by concomitant morphological changes in the brain tissue: the formation of foci of destruction, edema and diffuse loosening, hyperemia of the cortical vessels and subcortical white matter, hemorrhage, destructive and dystrophic changes in neurons and astrocytes, swelling of myelin fibers [2]. Conventional treatment for TBI do not allow to fully ensure the functional and structural regeneration of the brain. Technologies developed 
on animal models of $\mathrm{TBI}$ in vivo have not shown a significant effect in clinical trials yet [3].

A potential strategy for recovery and regeneration a damaged brain is considered to be the transplantation of neurogenic stem and/or progenitor cells (NSCs/NPCs) [4-6], which are located in the neurogenic areas of the adult mammalian brain and are able to be involved in regeneration and reparation in response to central nervous system (CNS) injury. In animal models of TBI, transplanted allo- and xenogeneic fetal NSCs/NPCs are capable of survival, migration and differentiation into neurons and astrocytes. NSCs/NPCs transplantation can also promote restore motor and cognitive functions [7-9]. Recently, the paradigm of regenerative effects of NSCs/NPCs has shifted from the concept of «cell replacement» (remodeling) to the concept of «functional or therapeutic plasticity» (modulation of the microenvironment). This is based on a wide range of regulatory paracrine effects of these cells, so called «bystander effects», that provide neuroprotection, modulation of inflammation and immune response and help to repair damaged neural tissue [10-13]. In this regard, much attention is paid to the study of factors produced by NSCs/ NPCs and thus enrich the culture media during cultivation as a released molecules or as a extracellular vesicles: neurotrophic, growth factors, morphogens, immunomodulatory cytokines (NGF, BDNF, NT-3, GDNF, TGF- $\beta 1$, TGF- $\beta 2$, VEGF, IL-1a, IL-1 $\beta$, IL-2, IL-4, IL-6, IL-10, IL-17, IFN- $\gamma$ TNF- $\alpha$ ), chemokines (CXCL12), prostaglandins (PGE2), microRNAs, etc. [10-19]. These secreted factors or NSCs/NPCs secretome $[11,20]$ are the mediators of bystander-effects, able to regulate a wide range of processes at the cellular, tissue, organ and systemic levels and are considered a key component of these regulatory mechanisms [12, 21-23]. Given the limited clinical use of cell therapy in the TBI treatment at this stage, it seems promising to study the effectiveness of regenerative effects of NSCs/NPCs conditioned media as a source of their secretome and a possible alternative to direct cell transplantation.

The development of new treatments for CNS injury requires mandatory prior testing of their effectiveness in in vitro and in vivo experiments. Cellular models in vitro are $90 \%$ close to the natural processes in vivo [24], so the urgent task is to find and create an optimal model of brain injury to study its own regenerative potential through endogenous repair mechanisms and assess possible therapeutic effects in transplantation of exogenous cells with regenerative potential. Such a model must be stable and reproducible with the possibility of adaptation to the tasks of a particular experiment.

To model the destructive processes in the nervous tissue at TBI, mechanical static (by transection, compression, stretching, barotrauma) or dynamic (by acceleration, braking) damage, hydrodynamic impact, chemical damage; different methods of culturing neural cells («brainon-chip», immortalized cell lines, primary and organotypic cultures, twodimensional 2D and three-dimensional 3D systems) are used [25]. The following in vitro models are available to simulate the loading conditions corresponding to clinical TBI and microscopic examination of cellular reactions in real time: stretching damage in 2D cultures [26, 27]; shear deformation and weight-drop injury of 3D-matrices containing cells [28,29]; stretching and oxygen-glucose deprivation of microvascular endothelial cells of the blood-brain barrier [30-32]; models of blast-induced TBI [33].

Most brain injuries are accompanied by local tissue ruptures that are difficult to investigate in vivo dynamics. For adequate reproduction of the tissue rupture model in vitro, mechanical transection (cross-section or cutting across) is used on organotypic brain slices [34] or «scratch injury» model on the culture of neural cells of the murine fetal brain cortex [35, 36 ]. At a section of a growth zone, cells are exposed to both compression and damages from their processes dissection, thus already established intercellular contacts are broken. The regeneration of injured tissue occurs due to cell migration, as well as their intensive proliferation. The simplicity of the transection or scratch model does not fully reflect the complexity of the processes in the damaged brain, but its important advantage is high reproducibility and clear edges of the injury. It allows to compare the effects on cells adjacent to the injury and cells of the un- damaged area [35, 36]. For the study, we selected a mechanical scratchinduced experimental model of TBI on a standardized culture of neural cells from brain tissue of rat fetuses 14-16 days of gestation (E14-16).

The PURPOSE of the study is to establish the effects of the conditioned media of rat fetal brain neurogenic cells (FBNCs) on the model of neurotrauma in neural cell culture in vitro.

\section{MATERIALS AND METHODS}

Outbred mature 3-months-old female rats weighing $220 \pm 10 \mathrm{~g}(\mathrm{n}=9)$ were used in the experiments. Animals were kept under standard conditions of the accredited vivarium of the State Institution «Romodanov Neurosurgery Institute, National Academy of Medical Sciences of Ukraine». All studies with experimental animals were carried out in compliance with legal norms and requirements of the Law of Ukraine №3447 IV «On protection of animals from cruelty», «European Convention for the protection of vertebrate animals used for research and other scientific purposes» (Strasbourg, 1986), taking into account the principles of bioethics and biosafety standards. Anesthesia was performed by diethyl ether, euthanasia - by ether overdose.

Isolation of FBNCs and obtaining their conditioned medium. Pregnant female rats at 14-16 days post coitum (E14-16) were anesthetized and the surgical site was treated with $96 \%$ ethanol. The abdominal cavity was dissected with sterile scissors, both horns of the uterus with the fetuses were placed on a sterile bandage, the fetuses were isolated $(n=89)$. Brain tissue was isolated under sterile conditions from the fetuses and washed in serum-free DMEM (Sigma, Germany) Blood vessels and meninges were removed, brain tissue was transferred to a fresh nutrient medium and mechanically dissociated by repeated pipetting. The obtained cell suspensions were pelleted by centrifugation for $5 \mathrm{~min}$ at $1500 \mathrm{rpm}$ and resuspended with fresh DMEM medium. The number and viability of the obtained cells were counted in a Goryaev chamber after staining with $0.2 \%$ trypan blue solution (Merck, Germany). The volume of the cell suspension at a concentration of $6,0 \cdot 10^{6}$ cells was adjusted to $6 \mathrm{~mL}$ by adding serum-free DMEM medium with $0.10 \mathrm{mg} / \mathrm{mL}$ concanavalin A (Serva, Germany), incubated for $2 \mathrm{~h}$ in a $\mathrm{CO}_{2}$ incubator (Nuve, Turkey) in standard conditions ( $95 \%$ humidity, $5 \% \mathrm{CO}_{2}, 37^{\circ} \mathrm{C}$ ). Next, the cells were pelleted by centrifugation for $5 \mathrm{~min}$ at $1500 \mathrm{rpm}$, the pellet were resuspended in DMEM serum-free medium and plated in plastic $35-\mathrm{mm}$ Petri dishes (SPL, Korea) at concentration $2 \cdot 10^{6}$ cells per plate. The cultures were kept in a $\mathrm{CO}_{2}$ incubator under standard conditions.

After $24 \mathrm{~h}$ of incubation of the FBNCs cultures, conditioned media were collected using a Pasteur pipette, and the protein concentration by Lowry was determined. The samples were aliquoted and frizzed at $-20^{\circ} \mathrm{C}$. Cells were fixed in $10 \%$ neutral formalin (Bio-Optica, Italy) and stained with rabbit anti-nestin antibodies (Sigma-Aldrich, USA) in dilution 1:100 for intermediate filament protein type VI as a marker of NSCs/NPCs. The visualization of the immunocytochemical staining was performed using the Immunoperoxidase Secondary Detection System kit (Millipore, USA). The number of nestin-positive cells in FBNCs cultures according to the counting in 10 randomly selected fields of view was $49.2 \pm 10.6 \%$.

Obtaining of the culture of rat neural cells (E14-16). The source of neural tissue cultures was the cerebral cortex and the hippocampus of rat fetuses. Pia matter were isolated from the brain with micro scissors, the cortex and hippocampus were isolated and minced with micro scissors into 1-2 $\mathrm{mm}^{3}$ fragments in CMF solution (BioWest, France). After that the tissue was dissociated by repeated pipetting with Pasteur pipettes. The resulting cells were pelleted by centrifugation for $5 \mathrm{~min}$ at $1000 \mathrm{rpm}$. The cell pellet was resuspended in DMEM medium (Sigma, Germany) supplemented with $20 \%$ fetal calf serum (BioWest, France), $8 \mathrm{mg} / \mathrm{mL}$ glucose, $100 \mathrm{IU} / \mathrm{mL}$ penicillin, $100 \mu \mathrm{g} / \mathrm{mL}$ streptomycin (Sigma-Aldrich, USA). The number and viability of the obtained cells were determined using a Goryaev chamber after staining with $0.2 \%$, trypan blue solution (Merck, Germany). The cells were seeded at $2 \cdot 10^{6}$ in $35-\mathrm{mm}$ Petri dishes (SPL, Korea) 
on cover slides pre-coated with polyethyleneimine (Sigma, Germany) for cell adhesion. Cultures were kept in a $\mathrm{CO}_{2}$ incubator (Nuve, Turkey) under standard conditions (95\% humidity, $5 \% \mathrm{CO}_{2}, 3{ }^{\circ} \mathrm{C}$ ). Lifetime observation and microphoto recording were performed during the experiment using an inverted microscope TS100 (Nikon, Japan).

Modelling of the neurotrauma in vitro. After achieving effective growth of the culture, when cells form a monolayer or a dense network $\left(5-7^{\text {th }}\right.$ day of cultivation), a transection was performed by scratching the cell growth zone with a metal blade. Cells that were detached from the surface of Petri dishes after the scratching were removed by a single wash with nutrient medium. As a result, a zone of damage to the monolayer (scratch area) with an average width of $\sim 450 \mu \mathrm{m}$ was formed.

The study of the effects of FBNCs conditioned media (E14-16) on the model of neurotrauma in vitro. In experimental cultures with a model of neurotrauma the FBNCs conditioned media was added once immediately after the transection. The effective dose $0.1 \mathrm{mg} / \mathrm{mL}$ by protein concentration was selected in previous experiments. As a standard culture conditions, $2 \mathrm{~mL}$ DMEM medium supplemented with $20 \%$ fetal calf serum and $8 \mathrm{mg} / \mathrm{mL}$ glucose was added to the control cultures after the transection of the growth zone. Accordingly, experimental groups were formed:

1. neurotrauma in vitro (control) - the culture of rat fetal neural cells (E14-16) with a mechanical model of neurotrauma under standard conditions of cultivation $(n=30)$;

2. neurotrauma in vitro + FBNCs conditioned media - the culture of rat fetal neural cells (E14-16) with a mechanical model of neurotrauma under the influence of FBNCs conditioned media at $0.1 \mathrm{mg} / \mathrm{mL}$ by protein, a single addition immediately after the transection $(n=30)$.

The cultures were kept in a $\mathrm{CO}_{2}$ incubator (Nuve, Turkey) under standard conditions ( $95 \%$ humidity, $5 \% \mathrm{CO}_{2}, 37^{\circ} \mathrm{C}$ ). Lifetime observation of the dynamics of culture growth was performed using an inverted microscope TS100 (Nikon, Japan). At the end of the experiment (the 13-15 day of cultivation, the $8^{\text {th }}$ day after the transection), the cultures were fixed in $10 \%$ neutral formalin (Bio-Optica, Italy) and stained with hematoxylineosin according to Carazzi and thionine according to Nissl. Also, immunocytochemical staining for nestin (marker of NSCS/NPCs, postmitotic neurons and early neuroblasts) and GFAP (glial cells and astrocyte marker) was performed. For this purpose, rabbit polyclonal anti-nestin antibodies at 1:100 (Sigma-Aldrich, USA) and anti-GFAP at 1:1000 (Millipore, USA) were used. The visualization of the immunocytochemical staining was performed using the Immunoperoxidase Secondary Detection System kit (Millipore, USA).

Microscopic and morphometric studies. Microscopic examination and photorecording of cell cultures cytological preparations were performed on a light optical photomicroscope Eclipse E200 (Nikon, Japan). Quantitative studies of control and experimental cultures were performed in 10 representative fields of view with a standard measuring scale of object-micrometer. Digital images were analyzed using ImageView software. Cytological changes were determined, namely total cell number, mitotic activity and morphometric parameters.

The cellular composition of the culture growth zone was assessed by phenotypic features of cells (shape of cytoplasmic cell bodies; presence, expression and density of processes; presence of signs of cell differentiation by morphological characteristics and expression of marker proteins) and their ability to form spatial histotypic structures. In all cultures, the migratory capacity of cells was assessed by analyzing the overgrowth of the transection zone. Using an inverted microscope, the migration of cells (as a part of multicellular clusters, layers or single cells), the density of migrated cells, and the overgrowth rate in the transection zone under the experimental conditions were assessed daily.

Morphometric analysis was performed by processing digital images of cell cultures in 10 randomly selected fields of view for each sample at the same magnification $\times 800$, determining on the test area $0.04 \mathrm{~mm}^{2}$ the width of the transection zone, the number of migrated cells and a migration distance.
Statistical analysis. Statistical analysis of the data obtained from the study was performed using the Statistica 8.0 software (StatSoft Inc., USA). Nonparametric methods of variation statistics were used: one-way ANOVA on ranks by Kruskal-Wallis for multiple comparison of several independent groups, Mann-Whitney U-test for pairwise comparison of independent groups, Wilcoxon test for pairwise comparison of dependent groups in the dynamics of observation. The normality of data distribution was determined by the Shapiro-Wilk test. Data are presented as Mean \pm SD and as Median (25\%; $75 \%)$. Differences were considered statistically significant at $p<0.05$, statistically highly significant - at $p<0.01$.

\section{RESULTS AND DISCUSSION}

Lifetime observation of rat neural cell cultures (E14-16) showed after $24 \mathrm{~h}$ of cultivation the presence of mostly round cells without processes, as well as single droplet-like cells with one short process (Fig. 1a). On the 2-3 $3^{\text {rd }}$ day of cultivation, cell migration was observed with the formation of microaggregates surrounded by single or arranged bundles of thin processes that were connected with each other. Droplet- and pear-shaped cells actively migrated along the surface of these structures (Fig. 1b), which eventually acquired numerous processes. On the $3-5^{\text {th }}$ day of cultivation, monolayer growths of poorly differentiated gliocytes dominated in the growth zone. On their surface, there persisted the groups of unipolar, pyramidal and pearshaped neuroblasts with optically dense cytoplasm, light nuclei and a large nucleolus. Cell bodies were narrow, with a typical branching of the processes (Fig. 1c). At the same time, monolayer associations of medulloblasts of typical phenotype were detected (Fig. 1d). Later (the $5^{\text {th }}-7^{\text {th }}$ day) the growth of glial cells formed the feeder layer for the survival of multipolar neurocytes with elongated processes (Fig. 1e). Immunocytochemical staining showed the predominance in cultures of nestin ${ }^{+}$and GFAP+ ${ }^{+}$cells (Fig. 1f, g).

The morphological characteristics of the obtained cultures of rat neural cells (E14-16) are generally similar to cell cultures from the cerebral cortex of E14 mice obtained by Lööv C. et al. $(2012,2013)$ [35, 36]. After cultivation in the form of neurospheres and subsequent seeding on the cover glasses, these cells during 8 days differentiated into the main cellular types of nervous tissue, including neurons and astrocytes. Our data also correspond to the observation of the presence of immature astrocytes in the cultures of neurogenic E14 mouse cells with the presence of intracytoplasmic filaments containing nestin and GFAP $[35,36]$.

DYNAMICS OF MORPHOLOGICAL CHANGES IN THE CULTURE OF NEURAL CELLS WITH A MECHANICAL MODEL OF NEUROTRAUMA UNDER DIFFERENT CONDITIONS OF CULTIVATION

Neurotrauma in vitro (control group). After the formation of a dense monolayer of neural cells (Fig. 2a) on the $5-7^{\text {th }}$ day of cultivation, the growth zone was scratched, to obtain an area of transection with smooth edges (Fig. 2b). In $24 \mathrm{~h}$ after the transection in control cultures we observed the migration of numerous long branched processes of cells from the edges of the growth zone along the entire length of the section (Fig. 2c). The cell bodies, preferably, did not leave the monolayer of the growth zone and did not migrate to the transection zone. During this period, no significant change in the width of the transection zone was observed.

In $48 \mathrm{~h}$ after the injury, single cells migrated to the transection area, which had round or teardrop-shaped cytoplasm with a clear nucleus and long processes. At the same time, numerous migrated processes were observed, which branched off with the formation of a veil-like network (Fig. 2d). The orientation of the processes was mainly perpendicular to the monolayer, directed toward the processes from the other edge of the transection. In most cases, the transection area was not completely inhabited by cells and their processes; only in one case the local filling of the entire width of the transection zone with processes was noted, but there were also areas that did not contain processes at all.

Some areas of depletion, reduction of the most part of the migrated processes, as well as degenerated cells with reduced processes were 
observed $72 \mathrm{~h}$ after the transection in the injured area (Fig. 2e). $96 \mathrm{~h}$ after the transection, an increase in destruction of the migrated cells was detected in the area of the injury (Fig. 2f), while cells in mitosis in the area of transection were not presented. Destruction in the transection zone increased by the $7^{\text {th }}$ day. At the same time, outside the injured area cells continued to grow. In the growth zone, the preservation of the dense cell monolayer was observed, in which the nestin ${ }^{+}$neuronal and GFAP+ ${ }^{+}$glial cells at different stages of differentiation (Fig. $\mathbf{2 g}, \mathbf{h}$ ) including 1-2 cells in mitosis per field of view (Fig. 2i) were observed.

Thus, after the transection of the growth zone in control neural cell cultures of rat brain (E14-16), mostly processes of cells whose bodies remained in the monolayer, as well as single undifferentiated or poorly differentiated cells, migrated to the injury zone at a short distance. Complete overgrowth of the transection area with the formation of a neuro-glia network during the study period (7 days) was not observed. Probably, the presence of tight contact between cells in the monolayer of the growth zone limit the migration of cells into free space, or the width of the damage is too large, which makes it impossible to contact the cell processes. At the same time, the growth zone in the intact area had a dense cell monolayer or formed a typical neuro-glia network; the cells retained the ability to mitotic division.

Our observations are largely consistent with the data of Lööv C. et al. (2012, 2013), obtained by the transection of the cell culture of the cerebral cortex cells of mice E14 $[35,36]$. The authors showed in time-lapse that within $24 \mathrm{~h}$ after the transection of the growth zone, astrocytes and neurons pulled out the processes and migrated in the directions to and along the injury, not growing into the scratching zone and not overgrow- ing it $[35,36]$. If the transection did not directly affect the cell nucleus or adjacent areas of the cytoplasm, the cells did not die. The neurites that regenerated grew along the lesion; neurons (identified by their round to oval cell bodies and distinct axons and dendrites) migrated toward and along the scratching zone and actively proliferated. Most cells in the culture expressed nestin and were not fully mature. Like neurons, astrocytes regenerated processes quickly after the injury, but did not migrate in response to the injury and very rarely crossed the scratched area, directing the processes mainly along it. $[35,36]$.

Interestingly, in contrast to the cultures with a transected growth zone, in intact cultures the migration of neurons did not have a specific direction, which indicates the induction of migration due to extracellular soluble signals. It is also important to note that astrocytes of the cerebral cortex of E14 mice, having the phenotype of a mature cell, expressed nestin [35]. The authors propose to distinguish cells by their typical shape and behavior in culture: astrocytes are tightly attached to the culture surface, while neurons migrated long distances on the surface of the cell layer of astrocytes, which corresponds to our data (see Fig. 1e). But, in our study of rat neural cell culture (E14-16), which lasted 7 days after the transection of the growth zone, the cells during the first $24-48 \mathrm{~h}$ directed their processes not only along the edges of the dissection of the growth zone, but also perpendicular to it, directing them to the opposite edge of the dissection zone. The cells also migrated to the transection zone.

Neurotrauma in vitro + conditioned media of FBNCs. In experimental cultures of rat neural cells, immediately after the transection of the growth zone on the $5-7^{\text {th }}$ day of cultivation, conditioned media of FBNCs $(0.1 \mathrm{mg} / \mathrm{mL}$ by protein) was added once. $24 \mathrm{~h}$ after the scratching and ad-
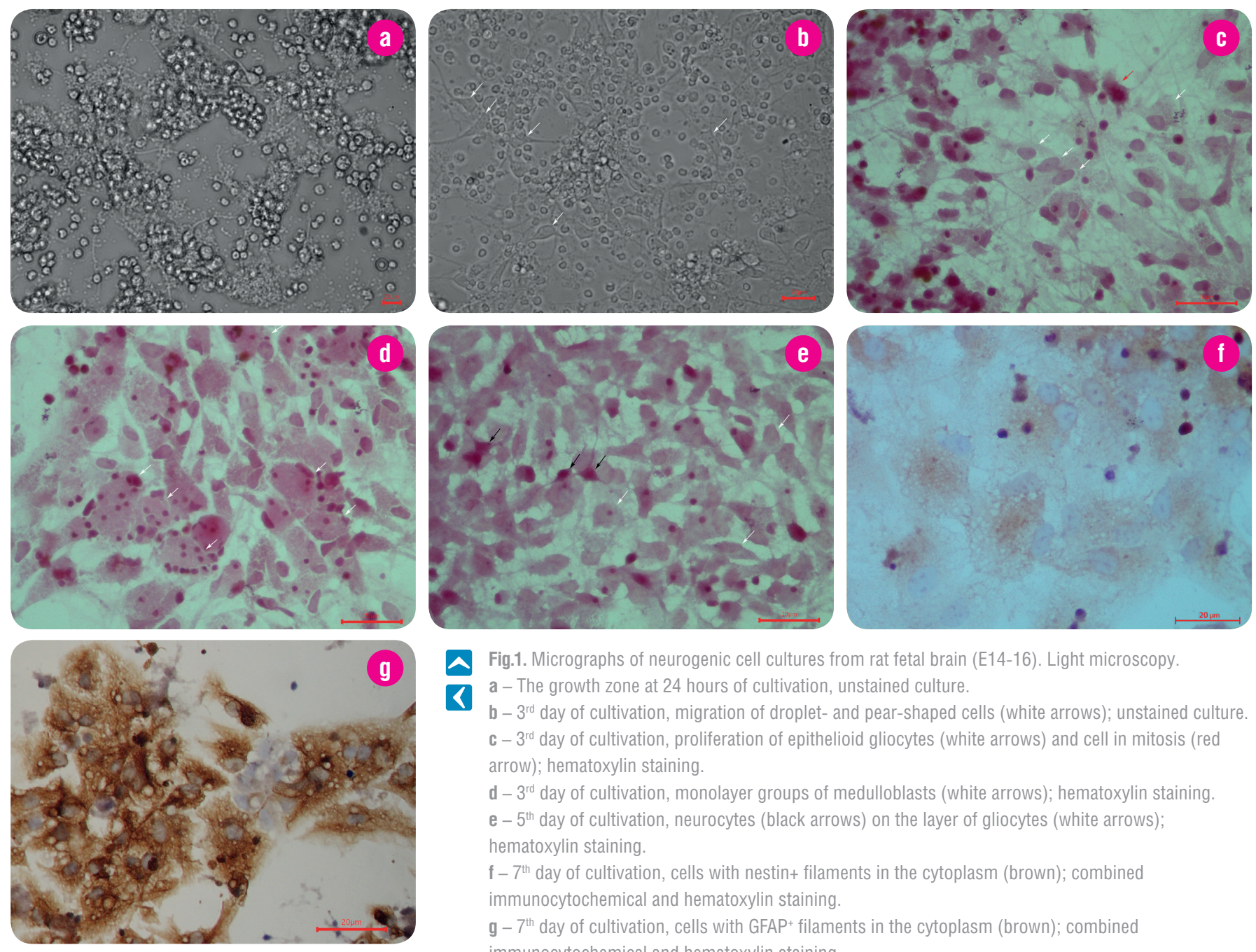

A Fig.1. Micrographs of neurogenic cell cultures from rat fetal brain (E14-16). Light microscopy.

a - The growth zone at 24 hours of cultivation, unstained culture.

b $-3^{\text {rd }}$ day of cultivation, migration of droplet- and pear-shaped cells (white arrows); unstained culture.

c $-3^{\text {rd }}$ day of cultivation, proliferation of epithelioid gliocytes (white arrows) and cell in mitosis (red arrow); hematoxylin staining.

d $-3^{\text {rd }}$ day of cultivation, monolayer groups of medulloblasts (white arrows); hematoxylin staining.

e $-5^{\text {th }}$ day of cultivation, neurocytes (black arrows) on the layer of gliocytes (white arrows);

hematoxylin staining.

$\mathrm{f}-7^{\text {th }}$ day of cultivation, cells with nestin+ filaments in the cytoplasm (brown); combined immunocytochemical and hematoxylin staining.

$\mathbf{g}-7^{\text {th }}$ day of cultivation, cells with GFAP+ filaments in the cytoplasm (brown); combined

immunocytochemical and hematoxylin staining. 

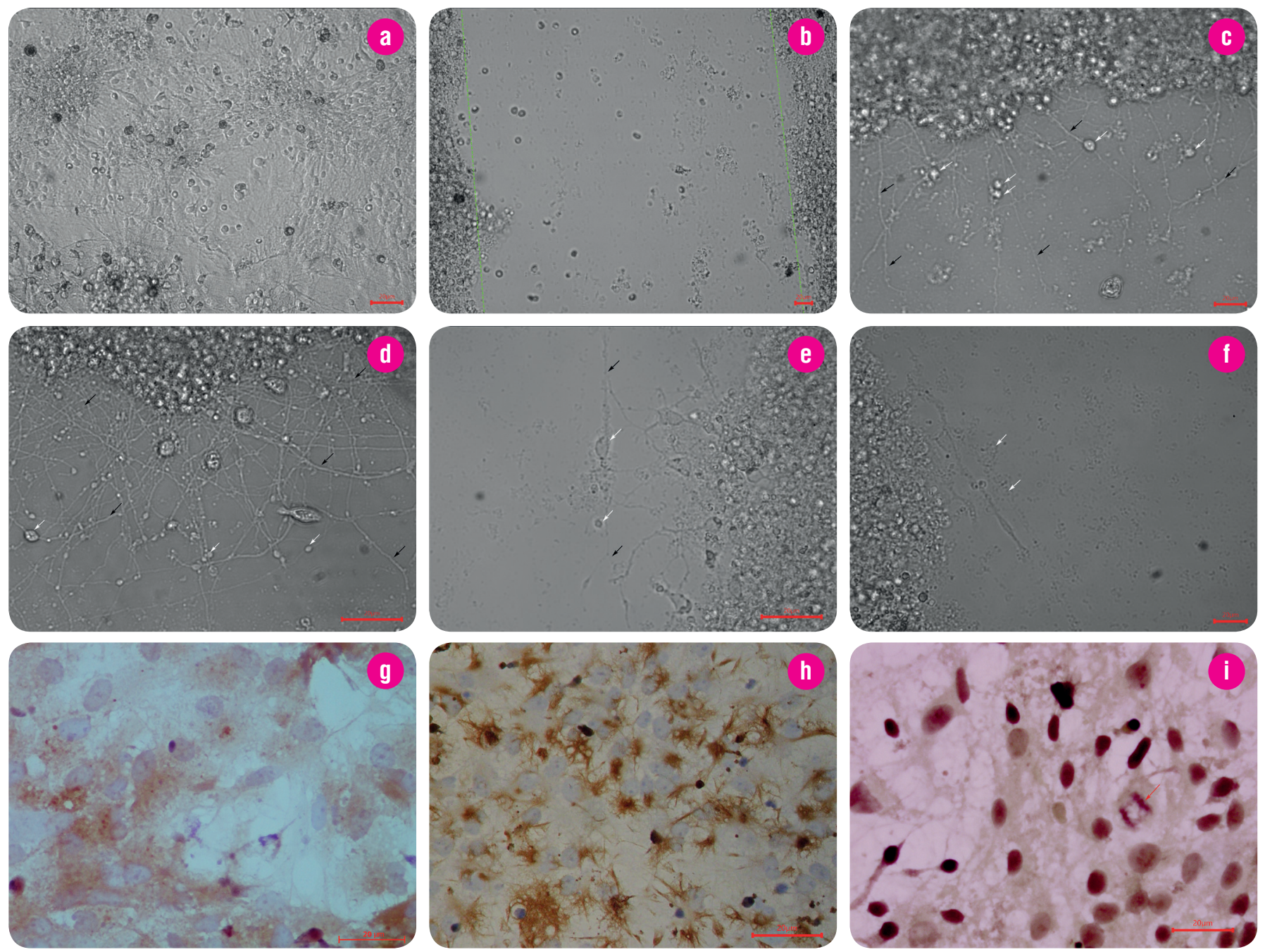

Fig. 2. Micrographs of neurogenic cell cultures from rat fetal brain (E14-16). Neurotrauma model in vitro, control. Light microscopy

a - growth zone of rat neural cell culture (E14-16), $6^{\text {th }}$ day of cultivation; unstained culture.

b - transection area (edges marked with a dotted line) immediately after the scratching of the growth zone, $6^{\text {th }}$ day of cultivation; unstained culture.

c - migration of cell processes (black arrows) and single cells (white arrows) from the edges of the transection area, $24 \mathrm{~h}$ after the scratching,

$7^{\text {th }}$ day of cultivation; unstained culture.

d - the migration of cells (white arrows) in the area of transection and the formation of a network of processes (black arrows), $48 \mathrm{~h}$ after scratching, $8^{\text {th }}$ day of cultivation; unstained culture.

$\mathbf{e}, \mathbf{f}$ - the reduction of processes (black arrows) and cell degeneration (white arrows) in the area of transection, 72 (e) and 96 (f) $h$ after the scratching, $9^{\text {th }}(e)$ and $10^{\text {th }}(f)$ day of cultivation; unstained culture.

$\mathbf{g}$ - intact area of the growth zone, cells with nestin + filaments in the cytoplasm (brown), $96 \mathrm{~h}$ after the scratching, $10^{\text {th }}$ day of cultivation; combined

immunocytochemical and hematoxylin staining.

$\mathbf{h}$ - intact area of the growth zone, cells with GFAP+ filaments in the cytoplasm (brown); $96 \mathrm{~h}$ after the scratching, $10^{\text {th }}$ day of cultivation; combined immunocytochemical and hematoxylin staining.

$\mathbf{i}$ - intact area of the growth zone, cell in mitosis (red arrow); $48 \mathrm{~h}$ after the scratching, $8^{\text {th }}$ day of cultivation; hematoxylin staining.

dition of FBNCs conditioned media, stratification of the edges of the transected growth zone and active migration of cell processes along the entire length of the transection zone were observed simultaneously in two directions: perpendicular to the monolayer, to the opposite side of the scratching site, and along the monolayer. Along with the migration of the processes, there was a migration from the monolayer of undifferentiated cells (Fig. 3a).

$48 \mathrm{~h}$ after the scratching and addition of conditioned media of FBNCs, we observed germination of cell processes at a considerable distance from the edges of the injured growth zone and the overgrowth of a large area of free space in the transection zone (Fig. 3, b). At the same time, active migration of poorly differentiated cells was detected, both individually and together, with the formation of clusters (Fig. 3c). Among the mi- grated cells, GFAP+ cells of glial phenotype with several processes were observed (Fig. 3D).

In $72 \mathrm{~h}$ after the transection and addition of conditioned media of FBNCs in the «wound» zone, we observed the «suturing» the edges of the transection zone using thin chains from process-bearing cells (Fig. 3e, f), and areas of displacement of whole layers from which there was a mass migration of differentiated GFAP+ cells with glial-like phenotype (Fig. 3g).

$96 \mathrm{~h}$ after the transection and addition of conditioned media of FBNCs we observed further stratification of the edges of the monolayer with the migration of whole layers of cells with processes (Fig. $3 \mathbf{h}$ ), including the $\mathrm{GFAP}^{+}$glial phenotype (Fig. 3i). In some areas, complete overgrowth of the transection zone was observed, and in several cases, there was 

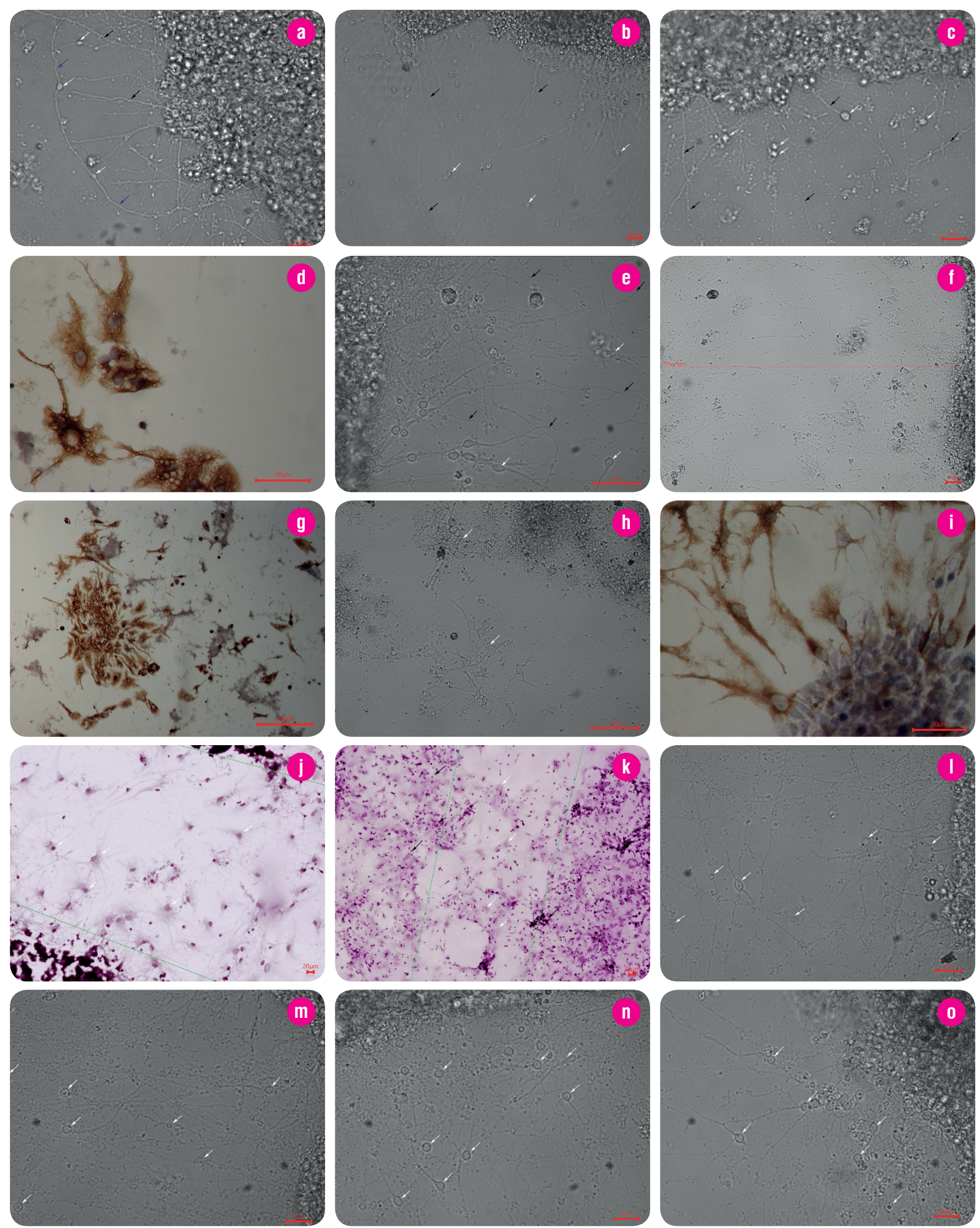

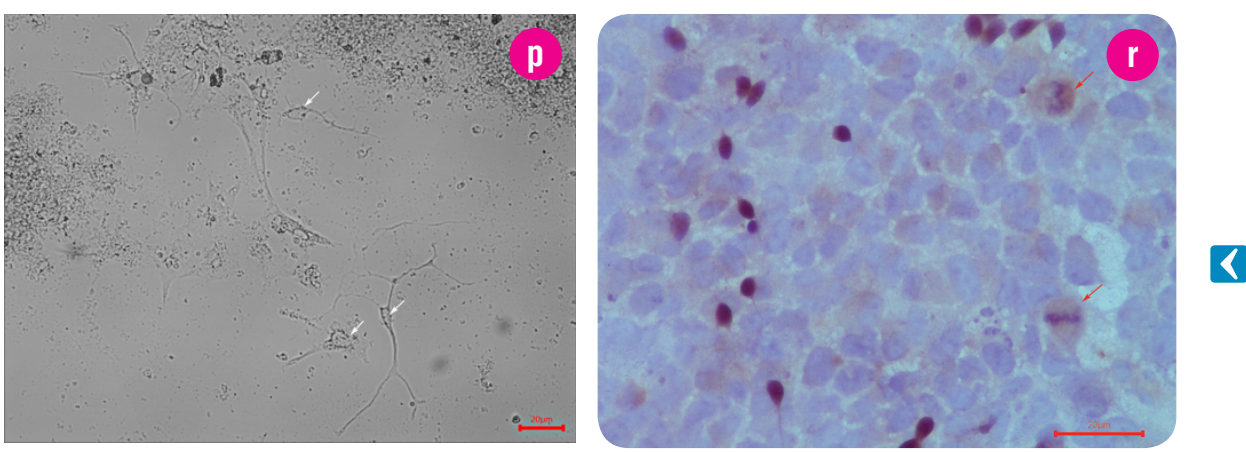

Fig. 3. Micrographs of neurogenic cell culture from rat brain (E14-16). Model of neurotrauma under the influence of conditioned media of FBNCs. Light microscopy.

\begin{abstract}
a - the migration of undifferentiated cells (white arrows) and processes (black arrows - perpendicular to the monolayer, blue arrows - parallel to the monolayer) from the growth zone. $24 \mathrm{~h}$ after the scratching and addition of conditioned media, $7^{\text {th }}$ day of cultivation; unstained culture.

b - overgrowth of the transection zone by cells (white arrows) and processes (black arrows). $48 \mathrm{~h}$ after the scratching and addition of conditioned media, $8^{\text {th }}$ day of cultivation; unstained culture.

c - migration of poorly differentiated cells (white arrows), both individually and together, with the formation of clusters. $48 \mathrm{~h}$ after the scratching and addition of conditioned media, $8^{\text {th }}$ day of cultivation; unstained culture.

d - migrated GFAP+ cells of the glial phenotype with several processes (brown); $48 \mathrm{~h}$ after the scratching and addition of conditioned media,

$8^{\text {th }}$ day of cultivation; combined immunocytochemical and hematoxylin staining.

$\mathbf{e}, \mathbf{f}$ - «suturing» of the edges of the transection zone with chains of cells (white arrows) and their processes (black arrows). $72 \mathrm{~h}$ after the scratching and addition of conditioned media, $9^{\text {th }}$ day of cultivation; unstained culture.

$\mathbf{g}$ - migration of the layers of GFAP+ process-bearing cells of the glial phenotype in the area of transection (brown); $72 \mathrm{~h}$ after the scratching and addition of conditioned media, $9^{\text {th }}$ day of cultivation; combined immunocytochemical and hematoxylin staining.

$\mathbf{h}, \mathbf{i}$ - migration of layers (white arrows) of the process-bearing cells of the glial phenotype in the transection zone. $96 \mathrm{~h}$ after the scratching and addition of conditioned media, $10^{\text {th }}$ day of cultivation; unstained culture $(\mathrm{h})$ and combined hematoxylin and immunocytochemical staining for GFAP+(i).

$\mathbf{j}, \mathbf{k}$ - complete overgrowth of the transection zone (the edges are marked by a dotted line, migrated cells - white arrows). $96 \mathrm{~h}$ after the scratching and addition of conditioned media, $10^{\text {th }}$ day of cultivation); hematoxylin staining.

$\mathrm{I}, \mathbf{m}, \mathbf{n}$ - migrated cells in the area of the transection (white arrows). $7^{\text {th }}$ day after the scratching and addition of conditioned media, $13^{\text {th }}$ day of cultivation; unstained culture.

$\mathbf{0}$ - migrated cells in the area of the transection (white arrows). $8^{\text {th }}$ day after the scratching and addition of conditioned media, $14^{\text {th }}$ day of cultivation; unstained culture.

p- migrated cells in the area of the transection with signs of degeneration (white arrows). $8^{\text {th }}$ day after the scratching and addition of conditioned media, $14^{\text {th }}$ day of cultivation; unstained culture.

$r$ - the intact area of the growth zone of rat neural cell culture (E14-16), in the field of view there are 2 cells in mitosis (red arrows). $8^{\text {th }}$ day after the scratching and addition of conditioned media, $14^{\text {th }}$ day of cultivation; hematoxylin staining.
\end{abstract}

a monolayer overgrowth of both terminals (Fig. $\mathbf{3 j}, \mathbf{k}$ ). These processes persisted on the $7-8^{\text {th }}$ day of observation (Fig. $\left.\mathbf{3 l}, \mathbf{m}, \mathbf{n}, \mathbf{0}\right)$. Morphological signs of degeneration of some cells migrated to the transection zone appeared only on the $8^{\text {th }}$ day of cultivation (Fig. 3p).

At the same time, outside the injury zone, the addition of conditioned media of FBNCs did not significantly affect the further growth of rat brain cell culture (E14-16): the monolayer structure of the growth zone and its density did not differ from control cultures; cells at different stages of mitosis - 1-2 in the field of view (Fig. 3r).

Therefore, after the transection and addition of conditioned media of FBNCs, in contrast to standard experimental conditions, active migration from the monolayer of cell processes was observed in the transection zone simultaneously with undifferentiated or poorly differentiated cells, as well as migration of cell clusters. Under the influence of conditioned media of FBNCs, differentiated cells in the transection zone were detected after $48 \mathrm{~h}$ of observation, in contrast to control cultures, where they were not detected at all. Unlike standard experimental conditions, under the influence of conditioned media of FBNCs we observed monolayer growths of differentiated cells immediately from the edges of the injured monolayer, and, in several cases, there was a complete overgrowth of the «wound» terminals. But, mainly, the overgrowth of the transection zone was observed locally: along the entire length of the incision zone, the areas of complete overgrowth alternated with the areas without signs of cell migration.

Thus, the study of the dynamics of morphological changes in the culture of neural cells of the fetal brain of rats (E14-16) with a mechanical model of neurotrauma in vitro reproduced by transection of the growth zone showed that within 24-48 hours of cultivation under standard nutrient medium composition processes of cells whose bodies remain in a monolayer, grow into the injury zone and also migrate single undifferentiated or poorly differentiated cells which move in an insignificant distance. In the next 72-96 hours of observation, cells and processes migrated to the area of transection degenerate. Overgrowth of the transection zone with the formation of a neuro-glia network during the observation period ( $96 \mathrm{~h}$ ) does not occur.

Under the influence of conditioned media from 24-h cultures of rat FBNCs (E14-16) in the dynamics of observation (24-96 h), in contrast to standard experimental conditions, in the transection zone there is an active migration of cell processes from the monolayer simultaneously with undifferentiated or poorly differentiated cells, cell clusters and their differentiation (48 $\mathrm{h}$ of observation). As well as the monolayer growths of differentiated cells, overgrowth of some areas of the transection zone along its entire length, and in several cases complete overgrowth of the terminals of the transection zone were observed. Therefore, conditioned media from 24-h cultures of rat FBNCs (E14-16), containing biologically active signaling mediators in a soluble form and in the extracellular vesicles (secretome), stimulate endogenous regeneration of neural cell culture in the damaged area: cell migration, germination of processes, monolayer formation and cell differentiation, as a result - overgrowth of the transection zone areas. At the same time, conditioned media from 24-h cultures of rat FBNCs (E14-16) do not affect the growth zone of rat fetal brain cell 
Table 1. Indicators of overgrowth of the transection zone under different experimental conditions in the model of neurotrauma in vitro.

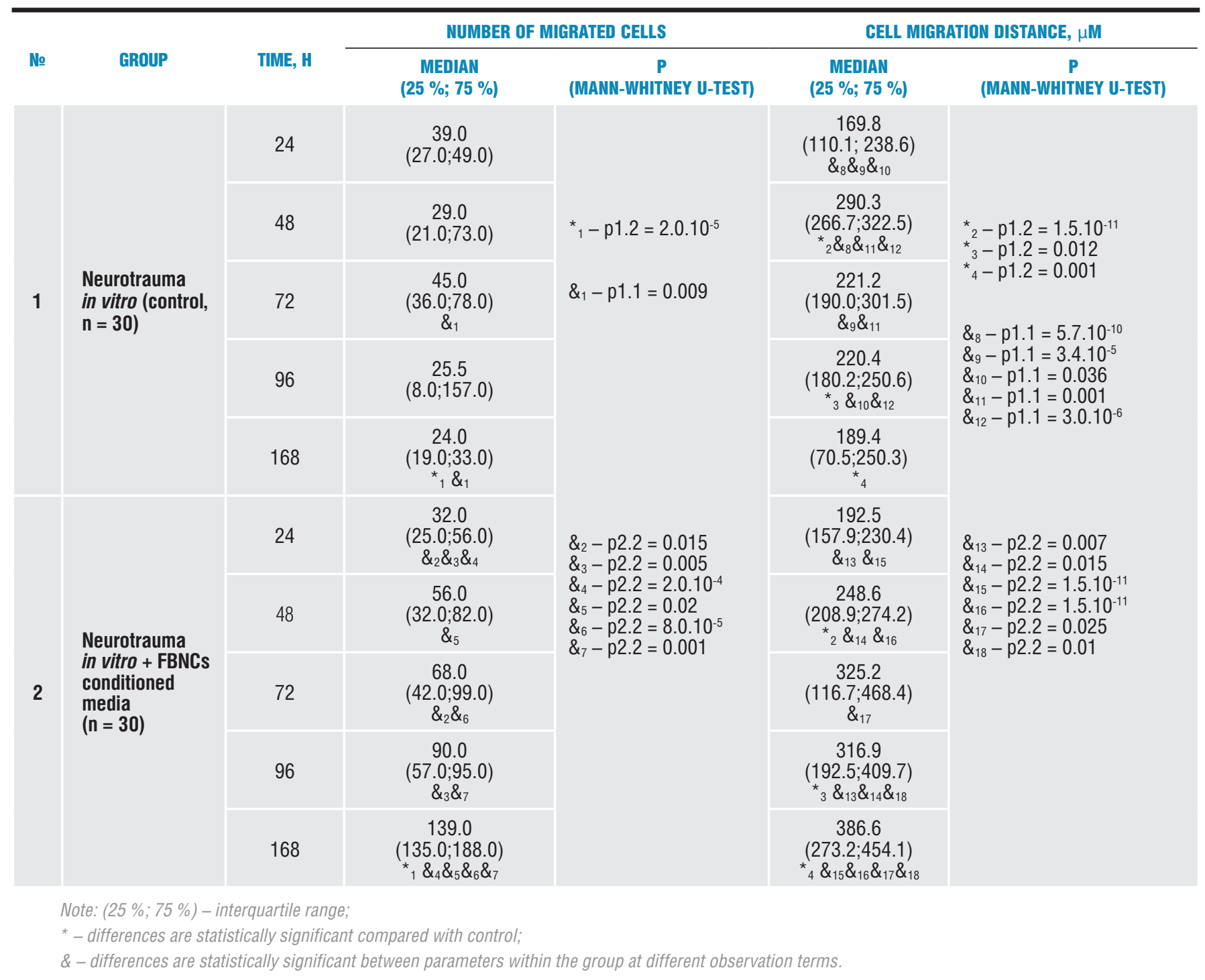

culture in the intact area: cell composition and size of the growth zone do not change; the ability of cells to mitotic division is preserved.

MORPHOMETRIC STUDY OF MORPHOLOGICAL CHANGES IN NEURAL CELL CULTURE WITH A MECHANICAL MODEL OF NEUROTRAUMA UNDER DIFFERENT CULTIVATION CONDITIONS

In control cultures with neurotrauma during the first 3 days of cultivation, the number of migrated cells in the transection zone did not change significantly, further decreasing from the $4^{\text {th }}$ to the $7^{\text {th }}$ day (table 1 ). The cell migration distance from the growth zone significantly increased from 24 to 48 hours of cultivation (1.7 times), further decreasing from the $3^{\text {rd }}$ to the $7^{\text {th }}$ day (1.5 times, table 1$)$.

When adding conditioned media of FBNCs we observed an increase in the number of migrated cells in the transection zone in the period from the $1^{\text {st }}$ to the $7^{\text {th }}$ day of cultivation: twice after $72 \mathrm{~h}$, almost three times after 96 $\mathrm{h}$, four times - up to the $7^{\text {th }}$ day of observation (table 1). The distance of cell migration from the growth zone significantly increased in the dynamics of observation (1.5-2.0 times on the 2-7 $7^{\text {th }}$ day of cultivation), exceeding the parameter in control cultures by 1.4-2.0 times after $96-168 \mathrm{~h}$ of cultivation (table 1).

Thus, the morphometric studies made it possible to confirm quantitatively the obtained patterns of stimulation of the transection zone (enhancement and acceleration of endogenous regeneration) in the culture of rat fetal neural cells (E14-16) with a mechanical model of neurotrauma in vitro under the influence of conditioned media from 24-h cultures of rat FBNCs (E14-16)

Obviously, the detected influence of conditioned media from 24-h cultures of rat FBNCs (E14-16), most of which are NSCs/NPCs, on the endogenous regeneration in the culture of neural cells of rat fetal brain with a mechanical model of neurotrauma in vitro is based on the cumulative effect of biologically active paracrine mediators (signaling molecules of secretome) produced by these cells in the culture medium [11, 20, 22, 37-40]. Secreted mediators are responsible for one of the main mechanisms of NSCs/NPCs effects, which means modulation of the local microenvironment around the affected area and activation of key inflammatory and regenerative programs in the CNS $[11,14,21]$, i.e. indirect effect, which in the scientific literature is called «bystander». Bystander effects are understood as the ability of these cells to secrete factors actively involved in regeneration processes, which include neuroprotective and immunomodulatory cytokines, neurotrophic and growth factors, morphogens, chemokines, etc. $[10,12]$. According to various sources, such mediators may include IL-1a, IL-1 $\beta$, IL-2, IL-4, IL-6, IL-10, IL-17, IFN- $\gamma$ TGF- $\beta 1$, TGF- $\beta 2$, TNF- $\alpha$, NGF, BDNF, NT-3, VEGF $[14-17,40]$. These factors may be present and manifest their effects in the conditioned media of FBNCs in the free soluble form, as well as contents of extracellular vesicles (cellular signal organelles) [11, 39, 40]. Since biologically active substances in the conditioned culture media 
of these cells are factors of their modulating and restorative effects, the conditioned medium as a source of secretome can be considered a key component of the microenvironment («niche») of these cells, which implements the regulatory effects of NSCs/NPCs in in vitro and in vivo models.

We previously showed that the conditioned medium of rat FBNCs (E12-16) in terms of $1 \mathrm{mg}$ of protein contained $1150 \mathrm{pg} / \mathrm{mL}$ BDNF, $120 \mathrm{pg} / \mathrm{mL}$ TGF- $\beta 1,74.0 \mathrm{pg} / \mathrm{mL}$ IFN- $\alpha$, as well as low concentrations of IL-1 $\beta$ and IL-4 [15]. In our opinion, BDNF and TGF- $\beta 1$ are most likely candidates from this list, responsible for the stimulating effect of conditioned media from 24-h cultures of rats FBNCs (E14-16), since they are known for their pleiotropic effects on the processes of cell proliferation, differentiation and survival and/or apoptosis, and its role in the morphogenesis of nervous tissue $[41,42]$.

It should be noted that direct targeted studies of the exact composition of conditioned media from NSCs/NPCs cultures (secretome, protein profiles, proteome libraries) are at an early stage [11]. Previous in vitro studies in this area dealt with the impact directly of the NSCs/NPCs themselves on other models of neurotrauma (organotypic slices) [34] and other CNS diseases, in particular spinal cord injury [13, 37, 43, 44]. Subsequent in vitro studies have investigated the effect of NSCs/NPCs conditioned media on stroke models (glutamate-induced excitotoxicity of cortical neurons) [22], ischemic hypoxia (hippocampal organotypic slices) [45], and Huntington's disease (transfection of neurons with huntingtin) [46], spinal cord injuries (organotypic slices, cultures of sensory neurons of adult rat dorsal root ganglia $[13,44])$ or neuromodulatory and potentiating effects [47]. Thus, the conditioned NSCs medium increased the viability of neurons due to antiapoptotic effects [22], showed a neuroprotective effect [45, 46], enhanced the growth of axons [44]. Addition to the culture of spinal cord microvascular endothelial cells (SCMECs) of exosomes derived from conditioned media of NSCs (NSCsExos) in the scratch test enhanced the migration and proliferation of SCMECs as well as formation of capillarylike tubules. [40]. Conditioned NSCs medium induced transdifferentiation of MSCs into NSC-like cells in vitro [48]. In addition, conditioned NSC/ NPCs media enhanced the neurogenic potential of other stem cells: 7-day cultivation of dental pulp stem cells under the influence of conditioned medium of immortalized human neural progenitor cells ReNCell VM promoted the formation of cells with characteristics of dopaminergic neurons (bipolar cells with large processes expressing neuronal markers NES, NR4A2, MSI1, TH) [47].

In general, our results on the regenerative effect of conditioned media of NSC/NPCs can be a theoretical basis for further promising developments in their study for the application in the treatment of brain trauma as a possible alternative to direct cell transplantation. It should be taken into account that conditioned media, in contrast to the cells, are relatively easier to manufacture, store, package and transport, which is important given the economic component of possible clinical application.

\section{CONCLUSION}

1. Under the conditions of the standard nutrient medium in the model of neurotrauma in the culture of the rat fetal brain neural cells in vitro the signs of endogenous regenerative process during 24-48 hours of cultivation and its reduction in the next 72-96 hours of observation were detected.

2. After a single treatment with conditioned media of rat fetal brain neural cells, an enhancement of reparative processes in the culture of neural cells with a model of neurotrauma in vitro was found for at least 7 days. The conditioned media do not affect the cell composition and mitotic activity of the intact area of cell culture.

\section{REFERENCES}

1. $\quad$ Peeters W, van den Brande R, Polinder S, et al. Epidemiology of traumatic brain injury in Europe. Acta Neurochir. 2015; 157(10):1683-96. D0I: 10.1007/s00701-0152512-7.

2. Pedachenko EG, Verhoglyadova TP, Morozov AN. Kliniko-morfologicheskaya kharakteristika tyazheloy cherepno-mozgovoy travmy [Clinical and morphological characteristics of severe traumatic brain injury]. Byul UAN - Bull NAS. 1998; 7:28-32. [In Russian]

3. Chayka AV, Zaben'ko YY, Labunets IF, Pivneva TA. Traumatic brain injury: pathogenesis, experimental models, prospects of cell-based therapy. JCOT. 2017; 5(2):209215. DOI:10.22494/cot.v5i2.78.

4. Ludwig PE, Thankam FG, Patil AA, et al. Brain injury and neural stem cells. Neural Regen Res. 2018; 13(1):7-18.

5. SanDekmak A, Mantash S, Shaito A, et al. Stem cells and combination therapy for the treatment of traumatic brain injury. Behav Brain Res. $2018 ; 340: 49-62$.

6. Weston NM, Sun D. The Potential of Stem Cells in Treatment of Traumatic Brain Injury. Curr Neurol Neurosci Rep. 2018; 18(1):1. D0I: 10.1007/s11910-018-0812-z.

7. Wennersten A, Meier X, Holmin S, et al. Proliferation, migration and differentiation of human neural stem/progenitor cells after transplantation into a rat model of traumatic brain injury. J Neurosurg. 2004; 100(1):88-96.

8. Skardelly $M$, Gaber K, Burdack $S$, et al. Long-term benefit of human fetal neuronal progenitor cell transplantation in a clinically adapted model after traumatic brain injury. J Neurotrauma. 2011; 28(3):401-14.

9. Rolfe A, Sun D. Stem Cell Therapy in Brain Trauma: Implications for Repair and Regeneration of Injured Brain in Experimental TBI Models. In: Kobeissy FH, editor. Brain Neurotrauma: Molecular, Neuropsychological, and Rehabilitation Aspects. 2015. Chapter 42. https://www.ncbi.nlm.nih.gov/books/NBK299210.

10. Martino G, Pluchino S, Bonfanti L, Schwartz M. Brain regeneration in physiology and pathology: the immune signature driving therapeutic plasticity of neural stem cells. Physiol Rev. 2011; 91(4):1281-304. D0l: 10.1152/physrev.00032.2010.

11. Willis CM, Nicaise AM, Hamel R, et al. Harnessing the Neural Stem Cell Secretome for Regenerative Neuroimmunology. Front Cell Neurosci. 2020; 14:590960. D0I: 10.3389/fncel.2020.590960.

12. Yang H, Wang C, Chen H, et al. Neural Stem Cell-Conditioned Medium Ameliorated Cerebral Ischemia-Reperfusion Injury in Rats. Stem Cells Int. 2018. https://doi. org/10.1155/2018/4659159.

13. Lladó J, Haenggeli C, Maragakis NJ, Snyder EY, Rothstein JD. Neural stem cells protect against glutamate-induced excitotoxicity and promote survival of injured motor neurons through the secretion of neurotrophic factors. Mol Cell Neurosci. 2004; 27(3):322-31. DOI: 10.1016/j.mcn.2004.07.010.

14. Mosher KI, Andres RH, Fukuhara T, et al. Neural Progenitor Cells Regulate Microglia Functions and Activity States. Nat Neurosci. 2012; 15(11): 1485-1487. DOI:10.1038/ nn.3233. 
15. Bacigaluppi M, Russo GL, Peruzzotti-Jametti L, et al. Neural Stem Cell Transplantation Induces Stroke Recovery by Upregulating Glutamate Transporter GLT-1 in Astrocytes. J Neurosci. 2016; 36(41):10529-44. DOI: 10.1523/JNEUROSCI.1643-16.2016.

16. Zhang $H$, Shao $B$, Zhuge $Q$, et al. Cross-talk between human neural stem/progenitor cells and peripheral blood mononuclear cells in an allogeneic co-culture model. PLoS One. 2015; 10(2):e0117432. D0I: 10.1371/journal.pone.0117432.

17. Jiao Q, Li X, An J, et al. Cell-Cell Connection Enhances Proliferation and Neuronal Differentiation of Rat Embryonic Neural Stem/Progenitor Cells. Front Cell Neurosci. 2017; 11:200. DOl: 10.3389/fncel.2017.00200.

18. Liubich LD, Semenova VM, Stayno LP. Influence of rat progenitor neurogenic cells supernatant on glioma 101.8 cells in vitro. Biopolym Cell. 2015 ; 31(3):200-208.

19. Gao M, Dong Q, Yao H, et al. Induced neural stem cells modulate microglia activation states vi CXCL12/CXCR4 signaling. Brain Behav Immun. 2017; 59: 288-299. D0I: 10.1016/j.bbi.2016.09.020.

20. Drago D, Cossetti C, Iraci N, et al. The stem cell secretome and its role in brain repair. Biochimie. 2013; 95(12):2271-85. D0l: 10.1016/j.biochi.2013.06.020.

21. Liang P, Liu J, Xiong J, et al. Neural Stem Cell-Conditioned Medium Protects Neurons and Promotes Propriospinal Neurons Relay Neural Circuit Reconnection After Spinal Cord Injury. Cell Transplantation. 2014; 23(1):S45-S56. DOI: http://dx.doi.org/10.3727/096368914X684989.

22. Geranmayeh MH, Baghbanzadeh A, Barin A, et al. Paracrine Neuroprotective Effects of Neural Stem Cells on Glutamate- Induced Cortical Neuronal Cell Excitotoxicity. Adv Pharm Bull. 2015; 5(4):515-521. DOI: 10.15171/apb.2015.070.

23. Doeppner TR, Traut V, Heidenreich A, et al. Conditioned Medium Derived from Neural Progenitor Cells Induces Long-term Post-ischemic Neuroprotection, Sustained Neurological Recovery, Neurogenesis, and Angiogenesis. Mol Neurobiol. 2017; 54(2):1531-1540. D0I: 10.1007/s12035-016-9748-y.

24. Morrison B, Elkin BS, Dollé JP, Yarmush ML. In vitro models of traumatic brain injury. Annu Rev Biomed Eng. 2011; 13:91-126.

25. Kumaria A. In vitro models as a platform to investigate traumatic brain injury. Altern Lab Anim. 2017; 45(4):201-11.

26. Sherman S, Phillips JK, Costa JT, et al. Stretch Injury of Human Induced Pluripotent Stem Cell Derived Neurons in a 96 Well Format. Sci. Rep. 2016; 6:34097. https:// doi.org/10.1038/srep34097.

27. Phillips JK, Sherman SA, Oungoulian SR, Finan JD. Method for High Speed Stretch Injury of Human Induced Pluripotent Stem Cell-derived Neurons in a 96-well Format. J Vis Exp. 2018; 134:57305. DOI: 10.3791/57305.

28. Bonder DE, Keating CE, Chandra N, et al. Modeling Traumatic Brain Injury In Vitro. In: Srivastava AK, Cox CS, editors. Pre-Clinical and Clinical Methods in Brain Trauma Research. Springer Protocols, Humana Press, New York, NY, 2018:37-69.

29. Tang-Schomer MD. Three-Dimensional In Vitro Brain Tissue Models. In: Srivastava AK, Cox CS, editors. Pre-Clinical and Clinical Methods in Brain Trauma Research. Springer Protocols, Humana Press, New York, NY, 2018:15-36.

30. Salvador E, Burek M, Förster CY. An In Vitro Model of Traumatic Brain Injury. Methods Mol Biol. 2018; 1717:219-227. D0I: 10.1007/978-1-4939-7526-6_17.

31. Ryou M, Mallet RT. An In Vitro Oxygen-Glucose Deprivation Model for Studying Ischemia-Reperfusion Injury of Neuronal Cells. Methods Mol Biol. 2018; 1717:229235. DOI: 10.1007/978-1-4939-7526-6_18.

32. Robinson BD, Shaji CA, Lomas A, Tharakan B. Measurement of Microvascular Endothelial Barrier Dysfunction and Hyperpermeability In Vitro. Methods Mol Biol. 2018; 1717:237-242. DOI: 10.1007/978-1-4939-7526-6_19.

33. Campos-Pires R, Yonis A, Macdonald W, et al. A Novel In Vitro Model of Blast Traumatic Brain Injury. J Vis Exp. 2018; 142. D0l: 10.3791/58400.

34. Vasilieva IG, Chopyk NG, Oleksenko NP, et al. Modelyuvannya neyrotravmi ta regeneratsii serotoninergichnikh providnikh shlyakhiv v umovakh kul'tivuvannya [Modeling of neurotrauma and regeneration of serotonergic conduction pathways in the conditions of cultivation]. Eksperimental'na i klinichna meditsina - Experimental and clinical medicine. 2016; 4:112-119. [In Ukrainian]

35. Lööv C, Hillered L, Ebendal T, Erlandsson A. Engulfing Astrocytes Protect Neurons from Contact-Induced Apoptosis following Injury. PLoS 0NE. 2012; 7(3):e33090. https://doi.org/10.1371/journal.pone.0033090.

36. Lööv C, Shevchenko G, Nadadhur AG, et al. Identification of injury specific proteins in a cell culture model of traumatic brain injury. PLoS One. 2013 ; 8 (2):e55983. DOI:10.1371/journal.pone.0055983.

37. Cheng Z, Bosco DB, Sun L, et al. Neural Stem Cell-Conditioned Medium Suppresses Inflammation and Promotes Spinal Cord Injury Recovery. Cell Transplant. 2017; 26(3):469-482. D0I: 10.3727/096368916X693473

38. Jia G, Yang H, Diao Z, et al. Neural stem cell conditioned medium alleviates Aß25-35 damage to SH-SY5Y cells through the PCMT1/MST1 pathway. Eur J Histochem. 2020; 64(2):3135:34-40.

39. Webb RL, Kaiser EE, Scoville SL, et al. Human Neural Stem Cell Extracellular Vesicles Improve Tissue and Functional Recovery in the Murine Thromboembolic Stroke Model. Transl Stroke Res. 2018; (9):530-9.

40. Zhong D, Cao Y, Li Ch-J, et al. Neural stem cell-derived exosomes facilitate spinal cordfunctional recovery after injury by promoting angiogenesis. Experimental Biology and Medicine 2020; 245: 54-65. DOI: 10.1177/1535370219895491.

41. Colucci-D'Amato L, Speranza L, Volpicelli F. Neurotrophic Factor BDNF, Physiological Functions and Therapeutic Potential in Depression, Neurodegeneration and Brain Cancer. Int J Mol Sci. 2020; 21(20):7777. DOI: 10.3390/ijms21207777.

42. Rodríguez-Martínez G, Velasco I. Activin and TGF-beta effects on brain development and neural stem cells. CNS Neurol Disord Drug Targets. 2012; 11(7):844-55. D0I: 10.2174/1871527311201070844.

43. Kamei N, Oishi $Y$, Tanaka N, et al. Neural progenitor cells promote corticospinal axon growth in organotypic co-cultures. Neuroreport. 2004; 15(17):2579-83. D0I: 10.1097/00001756-200412030-00004.

44. Merianda TT, Jin Y, Kalinski AL, et al. Neural Progenitor Cells Promote Axonal Growth and Alter Axonal mRNA Localization in Adult Neurons. Eneuro. 2017; 4(1):017116.2017. DOI: http://dx.doi.org/10.1523/ENEURO.0171-16.2017.

45. Lee NM, Chae SA, Lee HJ. Effects of neural stem cell media on hypoxic injury in rat hippocampal slice cultures. Brain Res. 2017; 1677:20-25. D0I: 10.1016/j. brainres.2017.09.018.

46. Lim H-C, Lee S-T, Chu K, et al. Neuroprotective effect of neural stem cell-conditioned media in in vitro model of Huntington's disease. Neurosci Lett. 2008; 435(3):17580. DOl:10.1016/j.neulet.2008.02.035.

47. Gnanasegaran N, Govindasamy V, Musa S, Abu Kasim NH. ReNCell VM conditioned medium enhances the induction of dental pulp stem cells into dopaminergic like cells. Cytotechnology. 2016; 68:343-353. DOI: 10.1007/s10616-014-9787-z.

48. Ma K, Fox L, Shi G, et al. Generation of neural stem cell-like cells from bone marrow-derived human mesenchymal stem cells. Neurol Research. 2011 ; 33:1083-1093. 


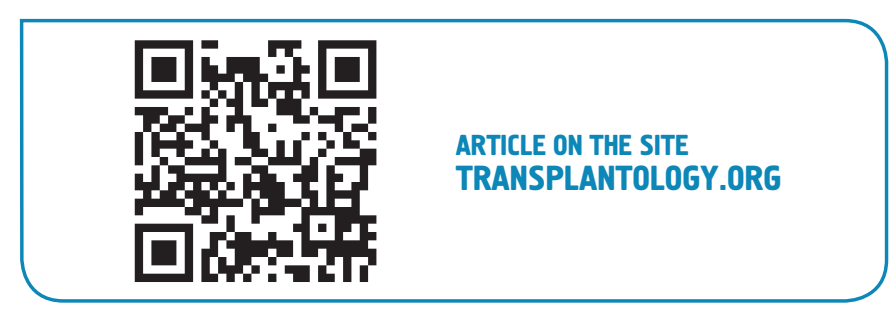

The authors declared no potential conflicts of interest with respect to the research, authorship, and/or publication of this article. 